
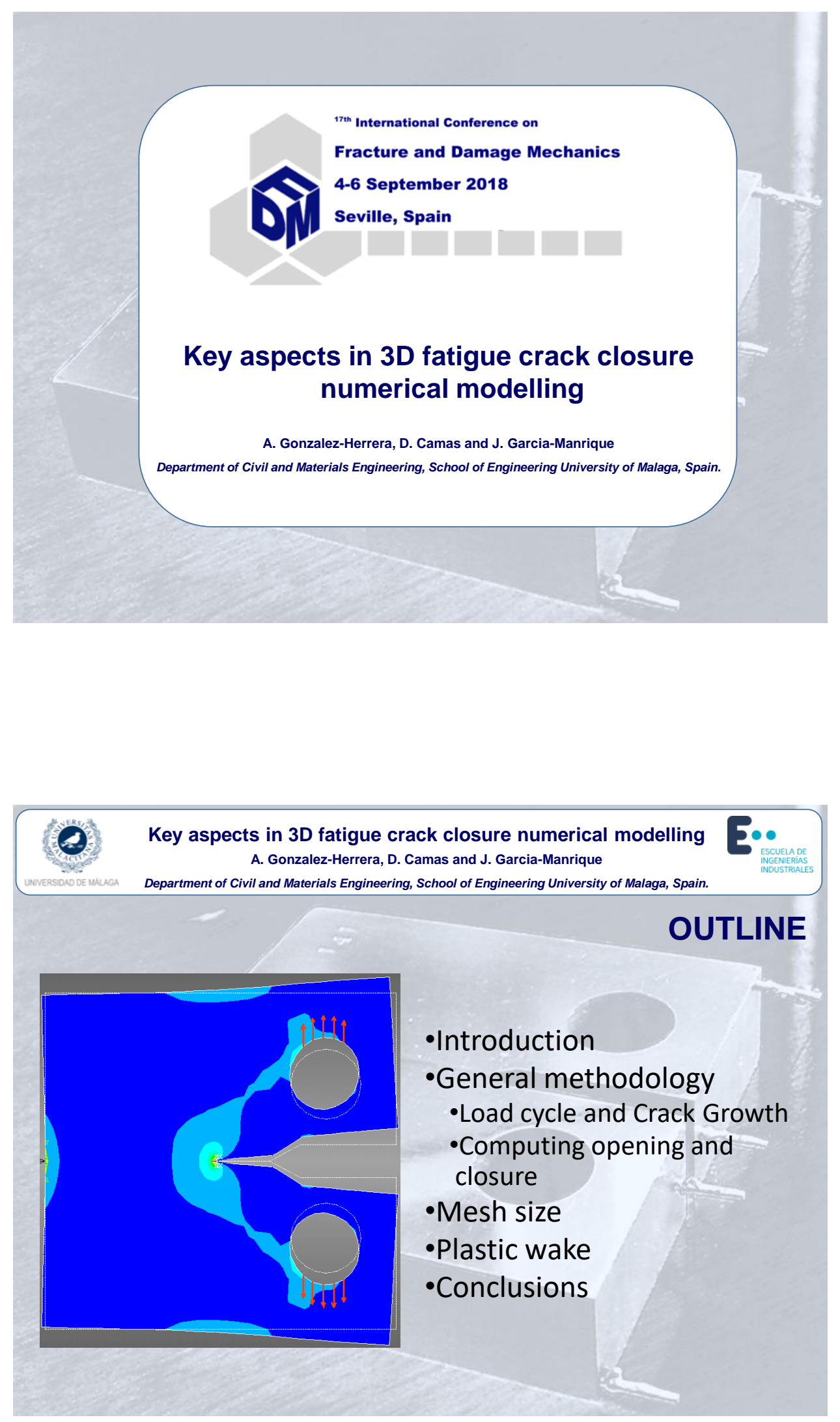

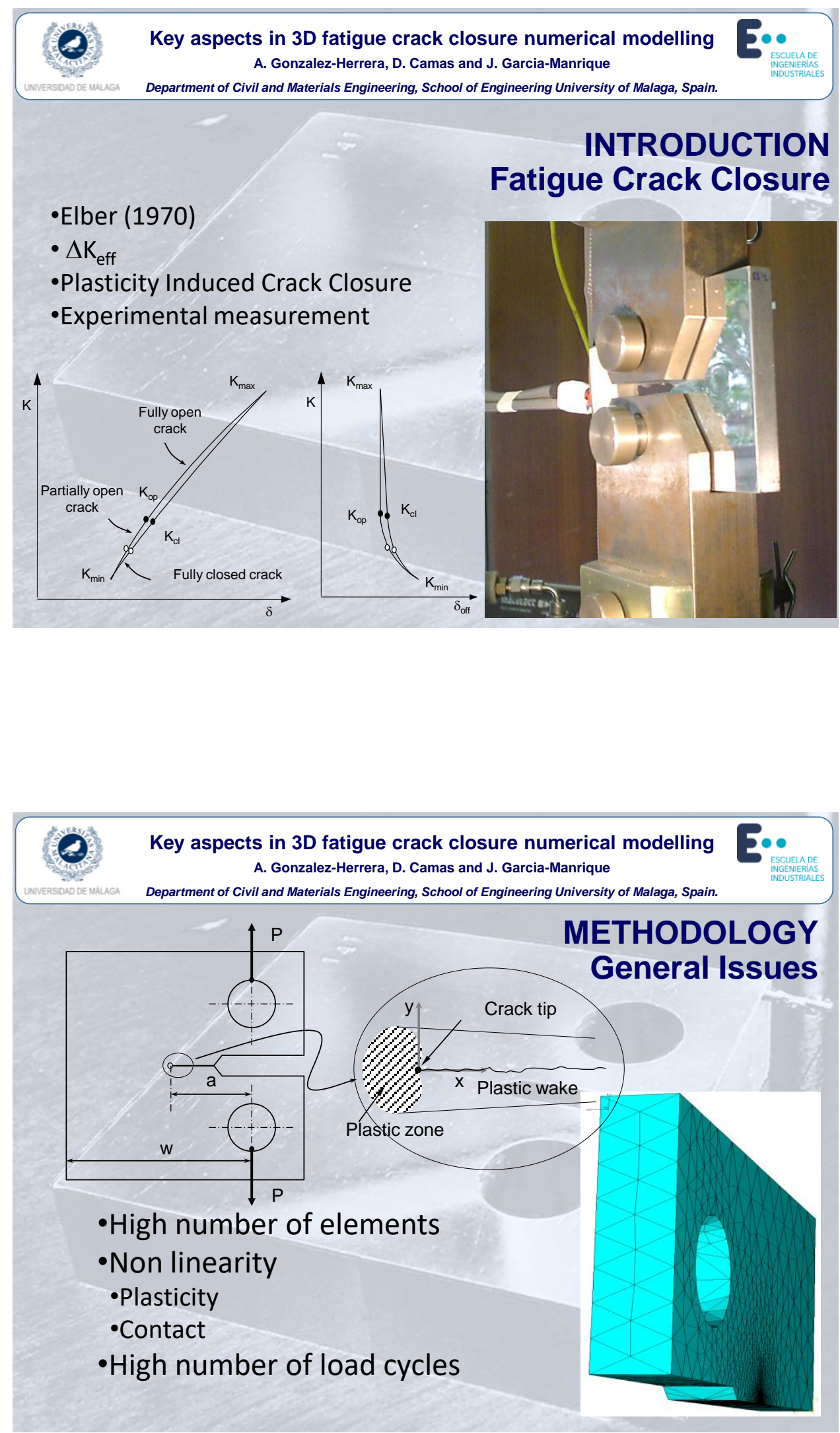

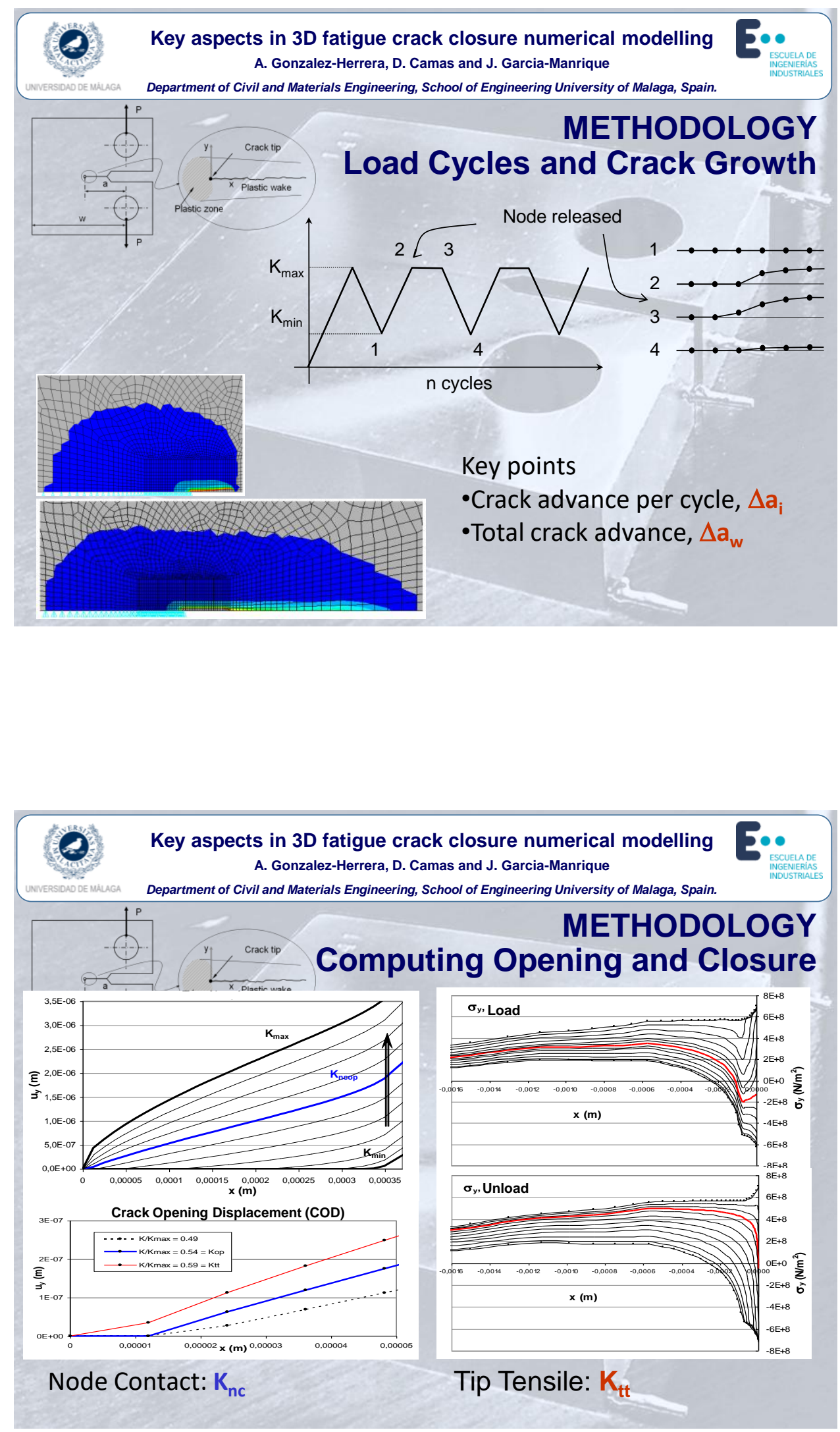

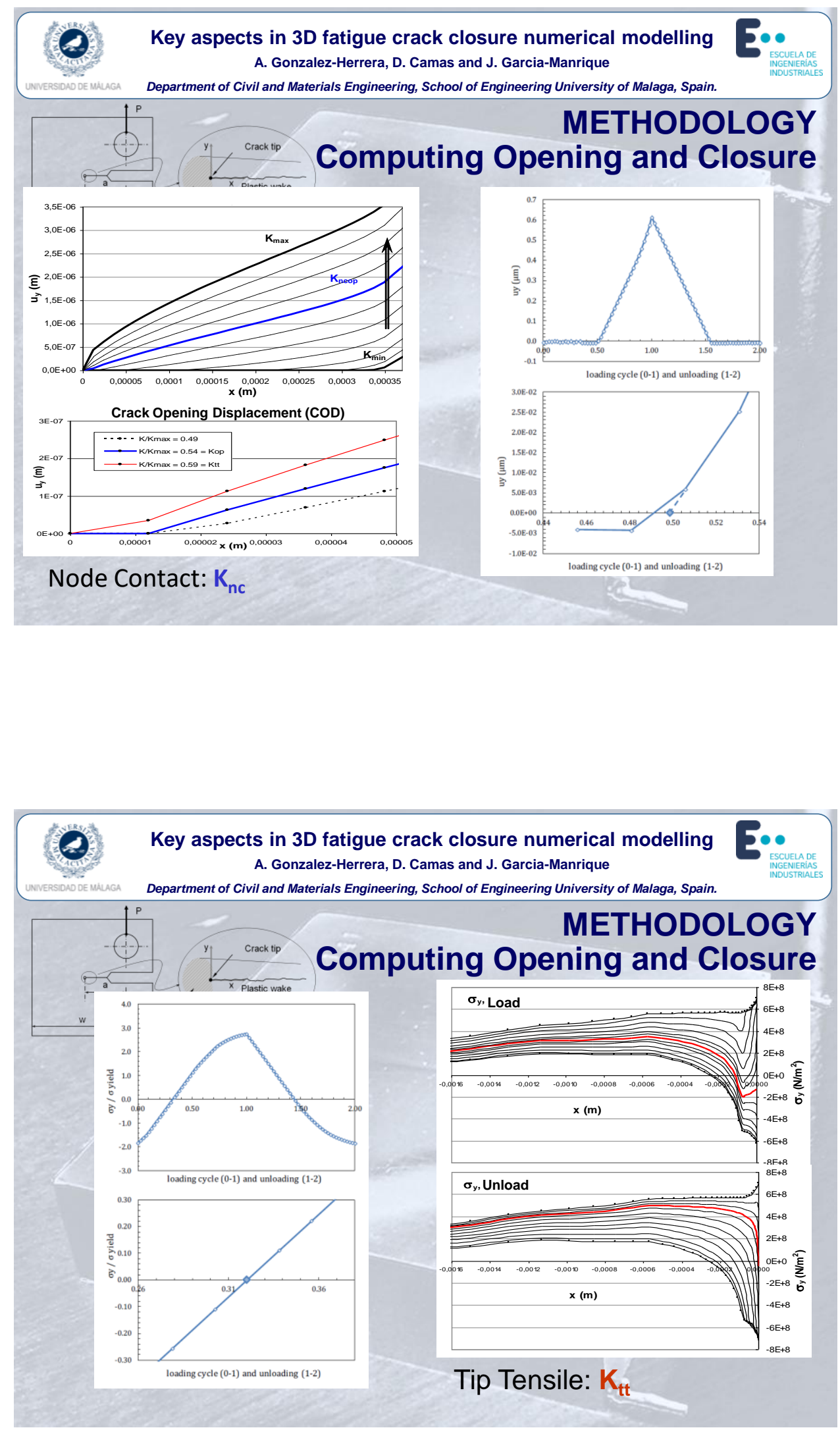

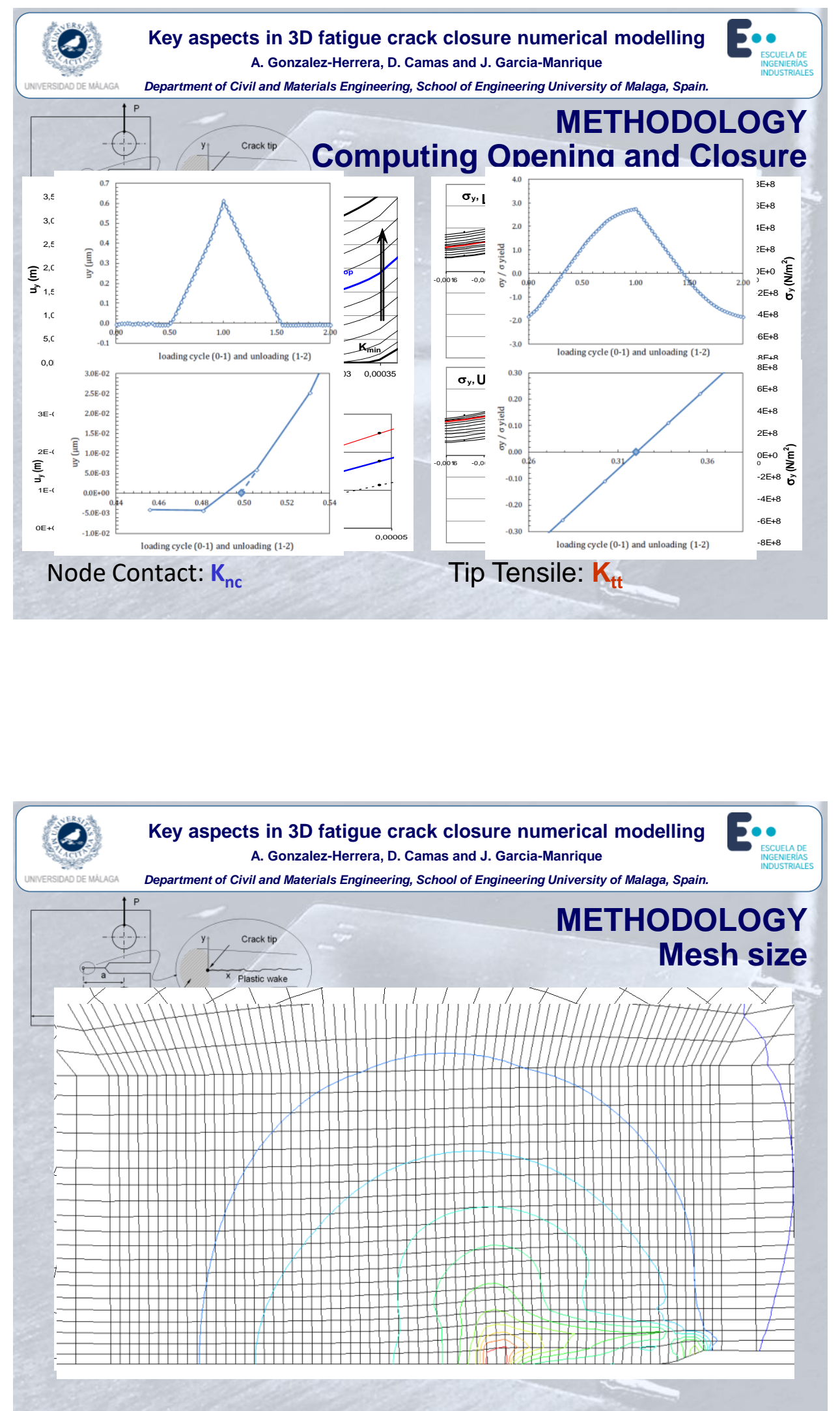


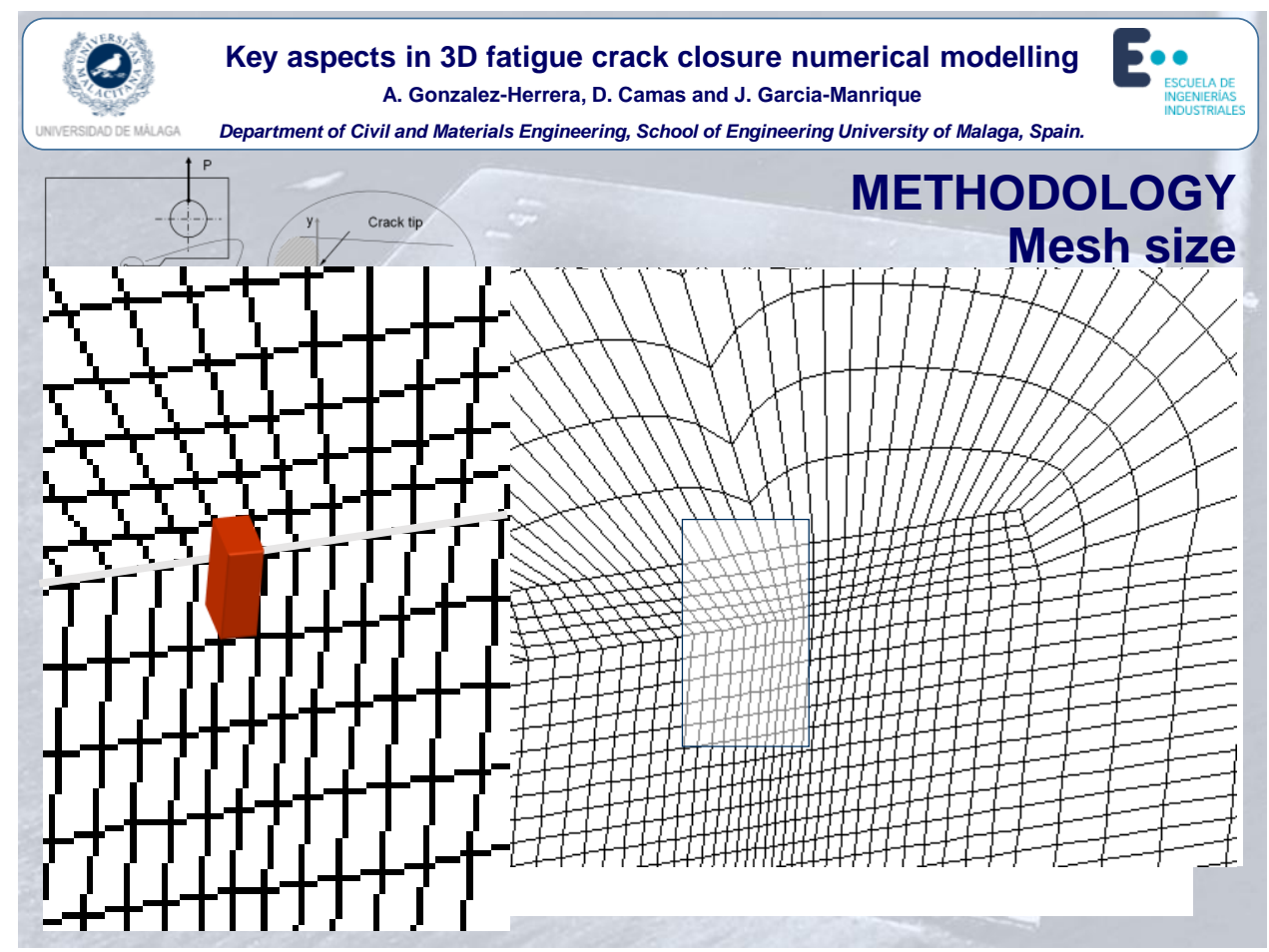

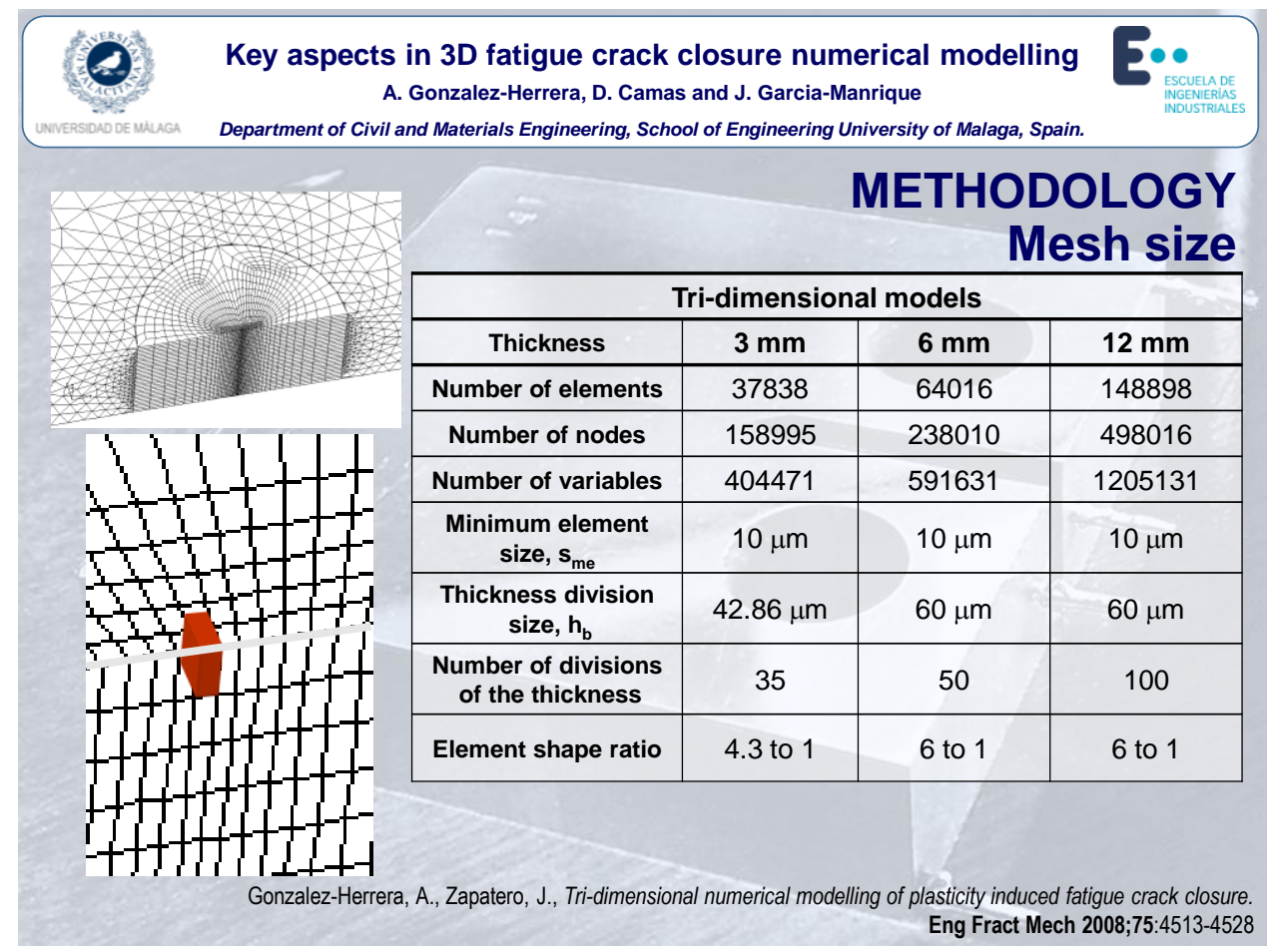



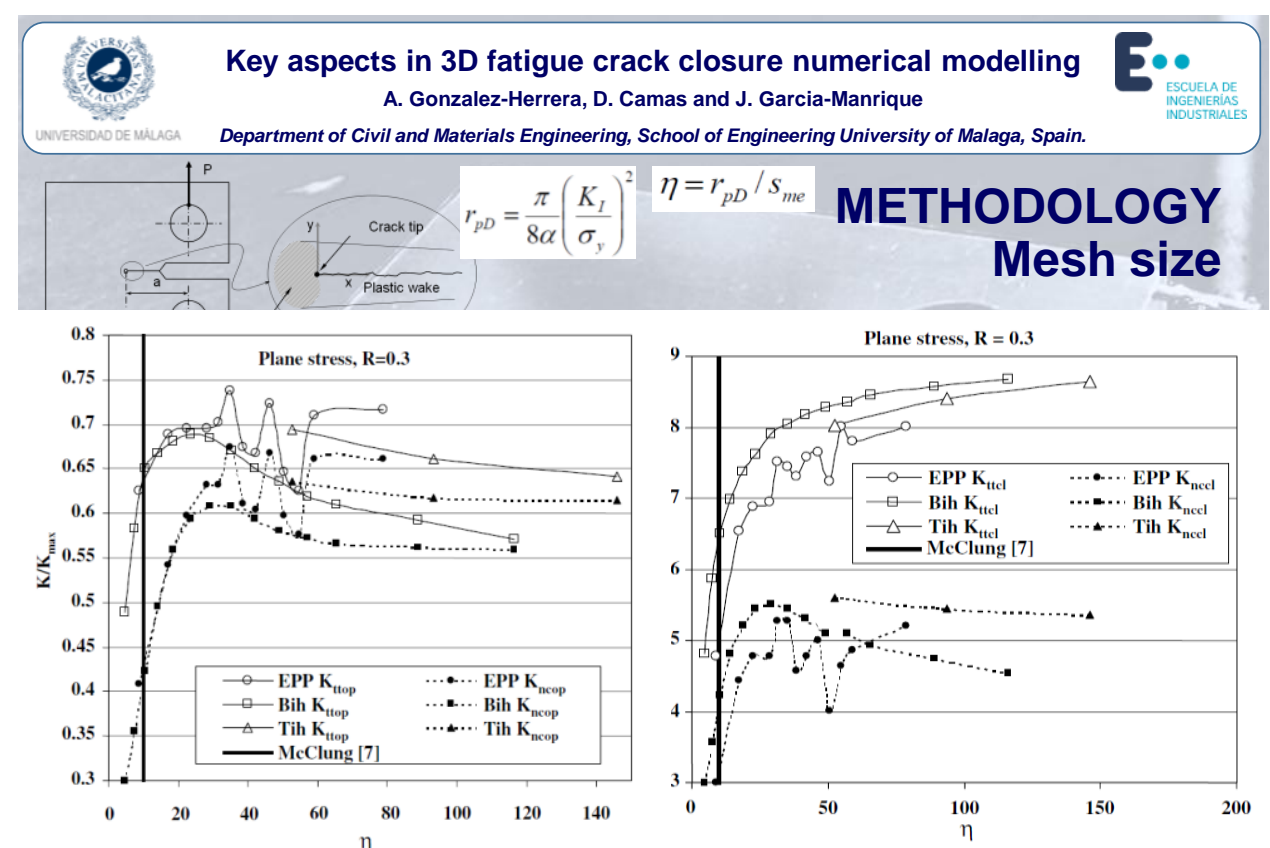

Gonzalez-Herrera A, Zapatero J. Influence of minimum element size to determine crack closure stress by the finite element method Eng Fract Mech 2005;72:337-55.

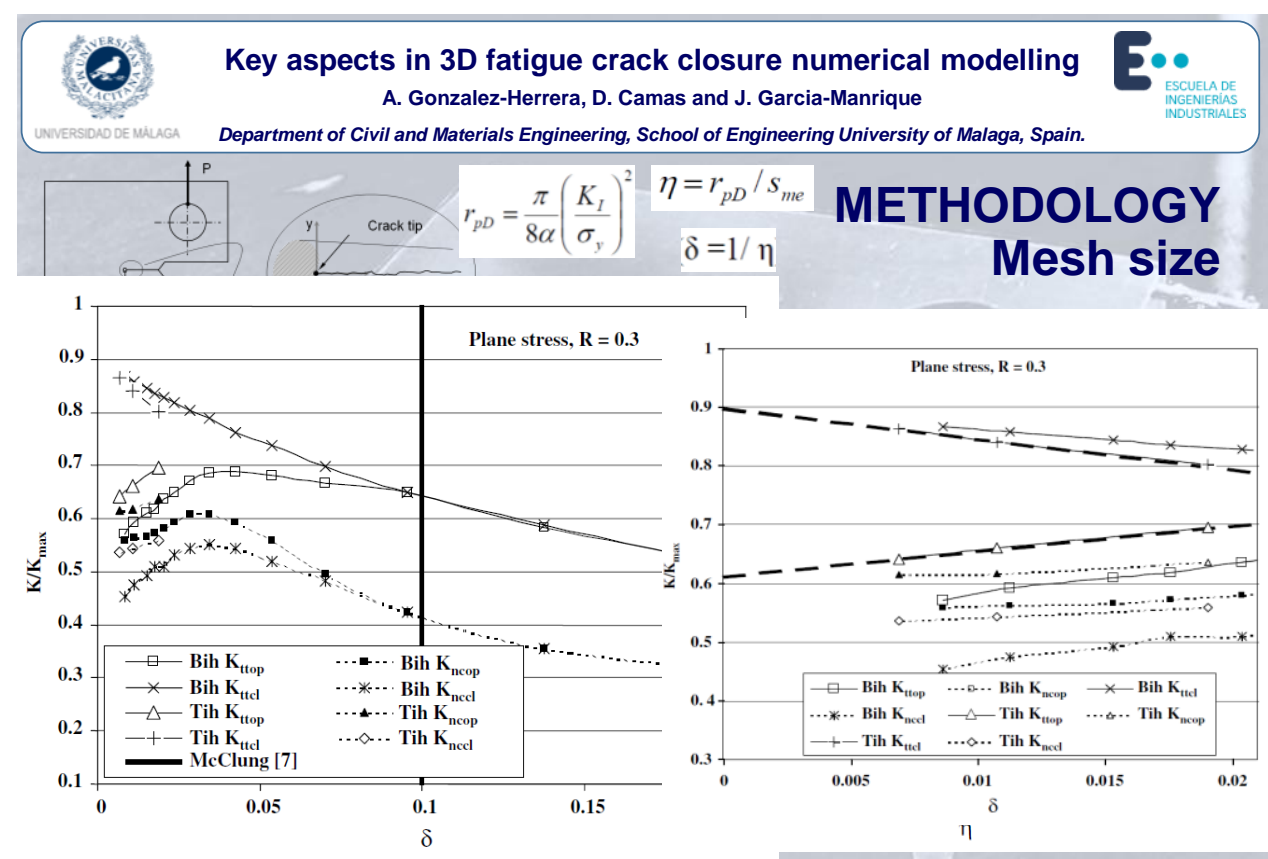

Gonzalez-Herrera A, Zapatero J. Influence of minimum element size to determine crack closure stress by the finite element method Eng Fract Mech 2005;72:337-55. 

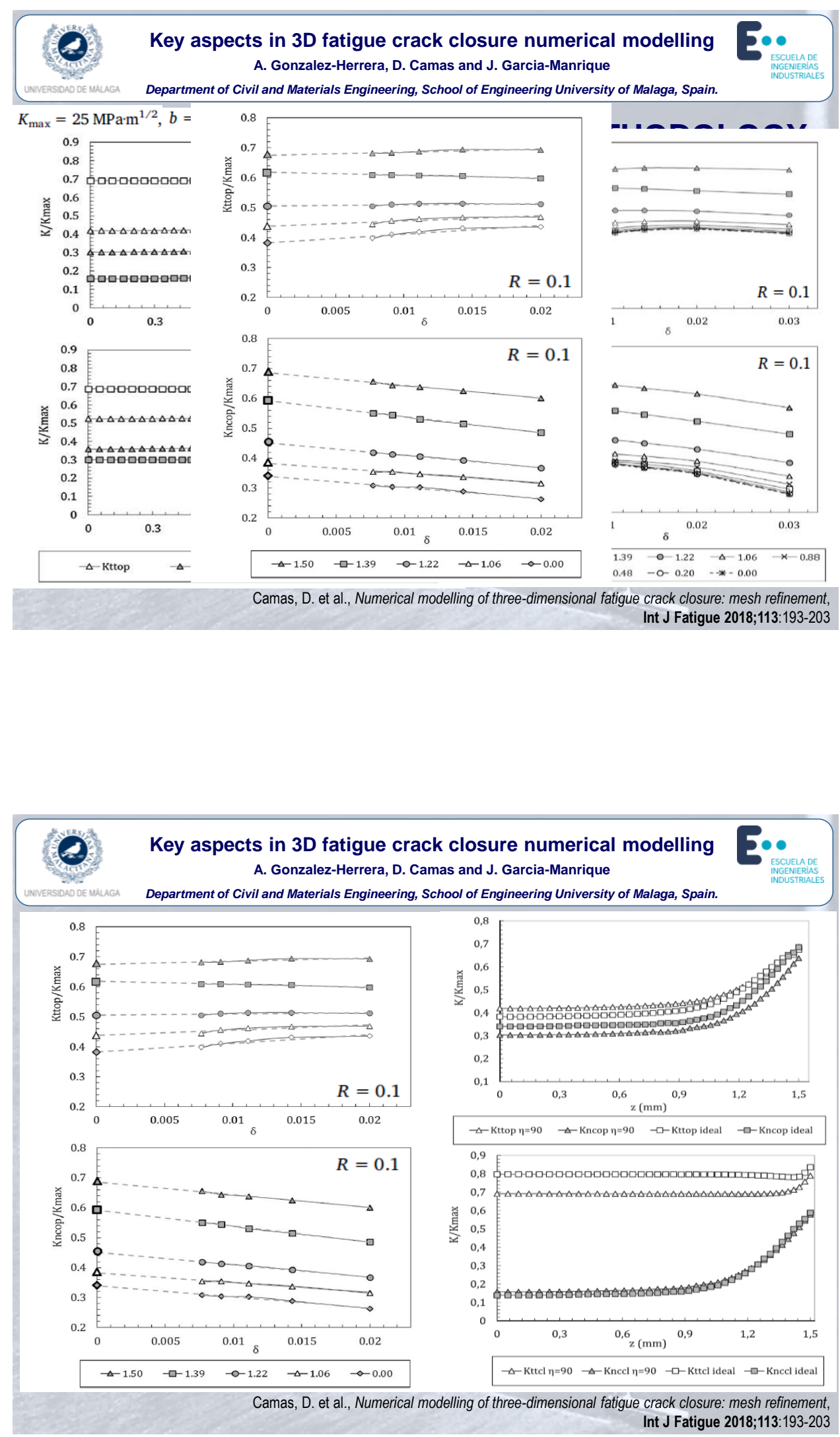

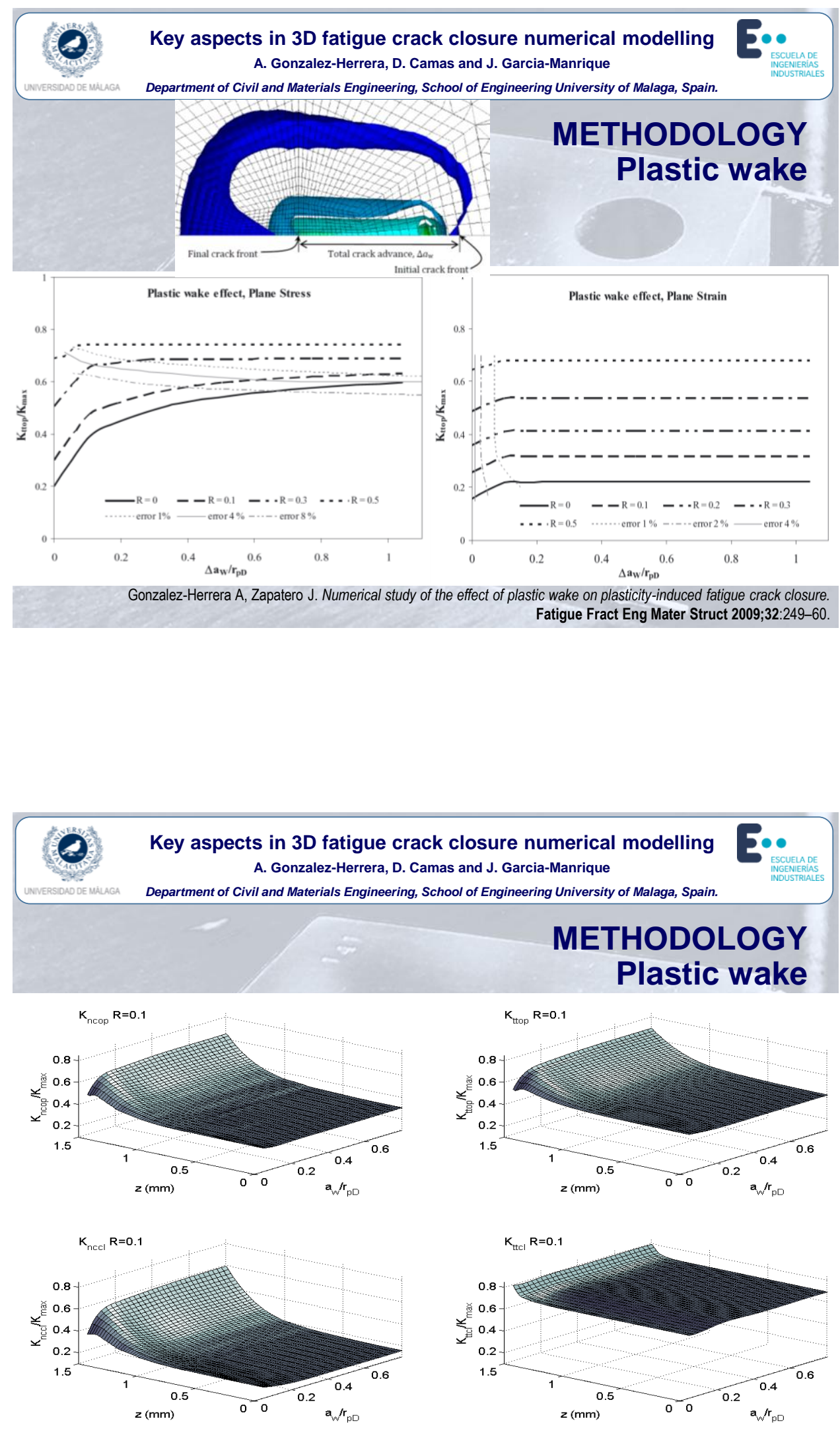

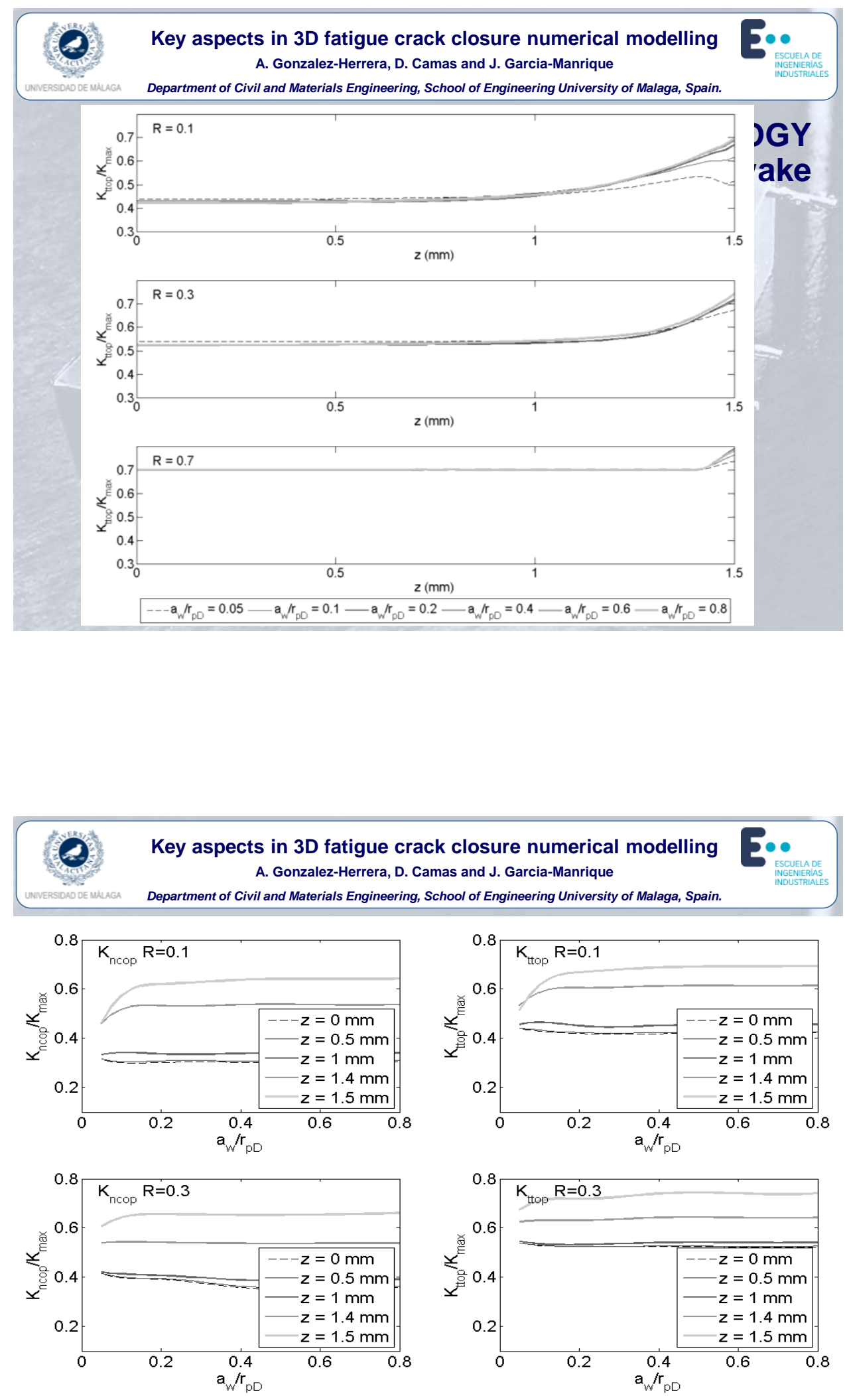


\section{Key aspects in 3D fatigue crack closure numerical modelling}

A. Gonzalez-Herrera, D. Camas and J. Garcia-Manrique

Department of Civil and Materials Engineering, School of Engineering University of Malaga, Spain.

\section{CONCLUSIONS}

-This paper summarises the main learning and recommendations from the numerical modelling experience of the authors.

- The influence of the minimum element size on crack opening and closure results has been analysed considering a three-dimensional model. The error can be minimized when a minimum element size is established as $\delta<0.015$ for $\mathrm{K}_{\text {ttop }}$ and $\delta<0.03$ for $\mathrm{K}_{\text {ncop }}$

- Regarding the influence of the plastic wake length, a plastic wake extension of $0.2 r_{p D}$ for $R=0.1$ and $0.1 r_{p D}$ for $R=0.3$ and $R=0.7$ would be acceptable. Results obtained in 3D case are less restrictive than those obtained in the 2D case. 